\title{
Effectiveness of Parent Focused Group Program on Obesity- Related Behavior \& Anthropometric Measurements among 6-12-Year-old Obese Children-A Pilot Study
}

\author{
Jomi John', Sushama SBai ${ }^{2}$, R. Vijayraghavan ${ }^{3}$ \\ ${ }^{1}$ Professor, INE, School of Medical Education, CPAS, Pala, Kerala, ${ }^{2}$ Former HOD, Dept. of Peadiatrics, Institute \\ of Child Health, Kottayam Medical College, Kerala, ${ }^{3}$ Research Director, Saveetha University, Chennai, India
}

\begin{abstract}
Background: Obesity is caused due to the mismatch between energy intake and expenditure, with food intake more than the requirements leading to an increase in Body mass index (BMI) as a body measurement parameter ${ }^{1}$. Parent focused group program is an intervention program where parents are involved in targeting the changes in obesity-related behavior of their obese children.
\end{abstract}

Objectives: To determine the effectiveness of parent-focused group programs on obesity-related behaviors of children aged 6-12 years.

\begin{abstract}
Method and Results: The study was conducted in two phases. The first phase included a survey design to identify overweight and obese children from two randomly selected schools as control and experimentalfrom the southern part of Kerala, India. The second phase includedan intervention design with a parent-focused group program for the program's experimental group, and effectiveness was analyzed from children's obesity-related behaviors. The key findings indicated that the parent-focused group program was effective in the pre-test and post-test scores of anthropometric measures in the experimental group for both boys and girls. The study suggested that parent-focused programs effectively bring changesin children's obesityrelated behavior, thus reducing the chances of getting overweight/obese.
\end{abstract}

Conclusion: Parent-focused group interventions are effective as a preventive strategy in reducing obesityrelated behavior among children.

Keywords: Parent focused group program, obesity-related behaviors, BMI.

\section{Introduction}

In an individual's lifespan, there are critical periods of development of obesity and its complications mostlyobserved during gestation, early in infancy, in the period of adiposity rebound, which usually occurs in 5-7 years of age and adolescence period. Behavioral and developmental processes have described these critical periods. Hence in this critical period, focus on preventive

\footnotetext{
Corresponding Author:

Jomi John

Professor, INE, School of Medical Education, CPAS, Pala, Kerala

e-mail-jomijohnac@gmail.com
}

efforts should be made ${ }^{2}$. There is a limited number of studies conductedin India aroundintervention programs for children in reducing obesity. Cochrane reviews have elicitedstudies involving parents, teachers, and children in the intervention programs. SeveralSystematic reviews have reported that obesityis a global problem in both developing and developed countries. Early age interventions can help in changing and building a healthy lifestyle among children. Interventions like healthy eating habits, healthy lifestyle modifications, physical exercise, screen time interventions can help in controlling obesity ${ }^{3}$.

Furthermore, involving parents in the intervention programs canmake a difference in bringing changes inobesity-related behavior among children ${ }^{4}$. An expert 
committee of the Maternal and Child Health Department of Boston, United States of America, concluded that parental skills are the basic foundation for having a successful intervention for managing pediatric obesity by targeting an increase in physical activity and reducing high fat and calorie foods in children. The report says further that the families need initial support in the weight management period and will gradually learn as a new behavior ${ }^{5}$.

A multi-component intervention based randomized controlled trial with 120 children aged 10-16 years from 11 schools in India suggested being effective in reducing BMI among obese children ${ }^{6}$. Therefore, raising the necessity to conduct studies on identifying effective strategies to improve obesity-related behaviors among school-going children.

Aims and Objectives: The study aimed to determine the effectiveness of the parent-focused group program on changes in obesity-related behavior and anthropometric measurements among children identified with overweight and obesity and to modify dietary habits, emotions \& attitudes towards eating, screen viewing \& sleep, and physical activities.

\section{Materials and Method}

Study type: An interventionalstudywas conducted in two phases. The first phase includeda survey design to identify overweight and obese children from two randomly selected schools as control and experimentalfrom an education district of the southern part of Kerala, India. The second phase includedan intervention design with a parent-focused group program for the experimental group, and the effectiveness of the program was analyzed from children's obesity-related behaviors.

Study area: The study was conducted among school children of randomly selected eight schools of Pathanamthitta Education Districtof South Kerala, India.

Study duration: The study was conducted between June 2017 toSeptember 2017

Study population: The participants included boys and girls in the age group of 6-12 years attending schools from class 1 to class 6 .

Inclusion and Exclusion criteria: The study included children belonging to both sexes in the age group of 6-12 years studying in class 1-6. Parents and children who knew both English and Malayalam were included in the study. Children having medical disorders, hormonal problems, metabolic disorders were excluded from the study. Also, both parents \& children who refused to participate in the study were excluded.

\section{Sampling technique \& Sample size calculation:}

The sample size was calculated based on the review of literature. The study was conducted in two phases in which a descriptive survey design was carried out in the first phase among 175 children studying in class 1-class 6 in the age group of 6-12 years. They were selected from two schools randomly. Initially a survey method was used to identify children as overweight and obesity.

In the first phase, the height, weight and body mass index were calculated for each child. Height of the child was measured to nearer $0.1 \mathrm{~cm}$ using a non flexible inch tape measure and noted in meters. Age of the child was derived using school records. Weight was measured using a calibrated standard weighing machine. BMI:-Body Mass Index is generally used for assessing the nutritional status. It is expressed as a ratio of weight in kilogram to height in meter square. The BMI was calculated using the formula: BMI $=$ Weight $(\mathrm{kg}) /$ Height $\left(\mathrm{m}^{2}\right)$.All the measurements were done after removing the shoes and with light clothing. Prevalence of obesity and overweight were categorized using the age and sex specific BMI cut offs for Indian children ${ }^{7}$. The demographic Performa was filled in first phase of study which had details related to child age, height, weight. The study was carried out during June 2017-September2017.

In the second phase that includes the evaluative phase where the before and after control group design was involved. The questionnaires on obesity related behavior, child eating behavior was assessed. Both child and parents were involved during the data collection . The eating habits of the children were assessed using questions asked to both parents and to the child. The sample who met the inclusion criteria from both the schools were identified. These two schools were taken as control and experiment. The control group (20/90) was taken from one school while the experimental group (26/85) was taken from other school to avoid any contamination. The experimental group was intervened with the parent focused program for a period of one month comprising of two teaching session. The post test measures were taken after a period of 3 months to evaluate the effectiveness of Parent group program. 
Ethical Consideration: Ethical permission was obtained from the institutional ethical committee of SaveethaUniversity(approval number 028/06/2017/IEC/ SU dated 09 June 2017). The study was conducted after obtaining necessary permission from the Headmaster as well as the District Director of Education in the month of June 2017. As the study involved both the child as well as the parent, informed consent and assent were obtained from both.

Data Collection Strategy: Appropriate tool was developed with the help of literature to collect background information on the age of the child, gender, place of residence, type of family, the annual income of the family, and the educational level of the parent. A second tool with 35 questions was developed to frame a questionnaire on obesity-related factors such as children's physical activity, dietary habits, television viewing patterns, and sleep patterns. Each item on the tool was given the highest score of 3 and the lowest score of 1 . Both the parent and child in the control and experimental group were assessed through pre-test, and intervention was given only to the experimental group

The parent-focused group program was planned and implemented as two sessions covering 120 minutes in each session in one month, in the presence of a pediatrician and dietitian only for the experimental group. Each parent was made aware of the focused group program and how they have to bring obesity-related behavior changes in the intervention phase. The sessions delivered knowledge on obesity-related factors and how as parents, they can manage obesity \& its complications, teach healthy eating habits, understand eating behaviors, and regulate healthy lifestyle, screen viewing \& sleep habits.After the intervention, the parents in the experimental group had telephonic conversations and feedback, and the post-baseline data were collected after ten months of the parent-focused group program.Hence, in the study, the parents were given regular feedback through telephonic sessions only in the experimental group, but no further feedback was provided for the control group.After three months, the same as the pretest assessment, the post-test evaluation was done on the parents and children.. The scores were recorded, and appropriate statistics were done

Statistics: The data were expressed in mean \pm SE, Median, Wilcoxon Signed rank sum focused group program.

\section{Results}

Table 1 shows the prevalence of boys with overweight were $21.6 \%$ and the prevalence of obese boys were $8.2 \%$ giving an overall prevalence (OW \& OB) of $29.8 \%$. The corresponding figures among girls were $16.7 \%, 5.1 \%$ and $21.8 \%$ respectively. The prevalence among boys was higher compared to that among girls. However, the difference was not statistically significant. The prevalence of overall overweight $\&$ obesity in both boys and girls was found to be $46(26 \%)$ which showed an increasing rise.

Table 2 shows the pre test and post test scores of obesity related behavior of the identified children in both control and experimental group. For the 12 items in the dietary habits subscale the experimental group showed an increase in median score from 22 to 23 which is statistically significant at $\mathrm{p}<0.001(\mathrm{Z}=4.204, \mathrm{~W}=283$ \& $\mathrm{p}<0.001)$. For the five items in the emotions and attitude subscale there is a slight increase in the experimental group from median scores 10 to 11 which is statistically significant at $\mathrm{p}<0.001 \quad(\mathrm{Z}=3.176, \mathrm{~W}=78, \mathrm{p}<0.001)$. Similarly for the five items in the subscale screen viewing and sleeping there is a very slight change in the median scores of control group from 6 to 6.5 but is not statistically significant $(\mathrm{Z}=1.58, \mathrm{~W}=2 \& \mathrm{p}=.195)$. In the subscale physical activity changes there is changes in median scores in the experimental group from 11 to 13 at $\mathrm{p}<0.001$, which is statistically significant $(\mathrm{Z}=4.218, \mathrm{~W}=276 \& \mathrm{p}<0.001)$.

Table 3 shows when comparing post-test scores of parameters height, weight and BMI of Control group and Experimental group .It shows that the Mean height \pm SE of control group after intervention is $148 \pm 1.19$ while in the Experimental group it is $134.5 \pm 1.19$ $\left(\mathrm{t}=8.014 \mathrm{p}<0.001^{* *}\right)$. Similarly the Mean Weight $\pm \mathrm{SE}$ of control group post test is $46.6 \pm 1.62$ while the post test Mean Weight \pm SE of theexperimental group is 34.9 \pm 1.25 at $\left(\mathrm{t}=5.81 \mathrm{p}<0.001^{* *}\right)$. Further the Mean $\mathrm{BMI} \pm \mathrm{SE}$ of Control group is $21.13 \pm 0.51$ and Experimental group is $19.22 \pm 0.51(\mathrm{t}=2.575 \mathrm{p}<0.013)$.

Table 4 shows that Mean \pm SE of parameter Height in both Control group and experimental group is significant at $\mathrm{p}<0.001$ taken at baseline and follow up. However the other two parameters weight \& BMI show no statistical significance within the groups.

Table 5 shows Mann whitney test showing T values and $\mathrm{P}$ values of eight subscales of eating behavior among 
children in both pre test and post test of con-exp group.

The results however show statistically no significance.

The sample
Limitations of the study: The pilot study was done with an intervention period of three months which was inadequate to observe changes in eating behavior.

Table 1: Prevalence of Overweight and Obese children according to gender and age

\begin{tabular}{|c|c|c|c|c|c|c|c|c|}
\hline \multirow{2}{*}{ Age (Yrs.) } & \multirow{2}{*}{ Number } & \multicolumn{3}{|c|}{ Boys } & \multirow{2}{*}{ Number } & \multicolumn{3}{c|}{ Girls } \\
\cline { 3 - 8 } & & OW & OB & NON OBESE & & OW & OB & NON OBESE \\
\hline $6-8$ & 19 & 4 & 0 & 15 & 19 & 2 & 1 & 16 \\
\hline $8-10$ & 30 & 6 & 4 & 20 & 27 & 5 & 0 & 22 \\
\hline $10-11$ & 48 & 11 & 4 & 33 & 32 & 6 & 3 & 23 \\
\hline Total & $\mathbf{9 7}$ & $\mathbf{2 1 ( 2 1 . 6 \% )}$ & $\mathbf{8 ( 8 . 2 \% )}$ & $\mathbf{6 8 ( 7 0 . 1 \% )}$ & $\mathbf{7 8}$ & $\mathbf{1 3 ( 1 6 . 7 \% )}$ & $\mathbf{4 ( 5 . 1 \% )}$ & $\mathbf{6 1 ( 7 8 . 2 \% )}$ \\
\hline
\end{tabular}

Table 2: Comparison of pretest and post test scores of obesity related behavior for Control and Intervention group.

\begin{tabular}{|c|l|c|c|c|c|c|c|c|c|}
\hline \multirow{2}{*}{$\begin{array}{c}\text { Sl. } \\
\text { No }\end{array}$} & Subscale & \multicolumn{4}{|c|}{ Control group } & \multicolumn{4}{c|}{ Intervention group } \\
\cline { 2 - 11 } & $\begin{array}{c}\text { Pretest } \\
\text { median }\end{array}$ & $\begin{array}{c}\text { Post test } \\
\text { median }\end{array}$ & $\mathbf{Z}$ & $\mathbf{p}$ & $\begin{array}{c}\text { Pretest } \\
\text { median }\end{array}$ & $\begin{array}{c}\text { Post test } \\
\text { median }\end{array}$ & $\mathbf{Z}$ & $\mathbf{p}$ \\
\hline 1 & Dietary habits & 23 & 23 & 0.333 & 0.844 & 22 & 23 & 4.204 & $<0.001^{* *}$ \\
\hline 2 & Emotions and attitude towards eating & 11 & 11 & 1.508 & 0.206 & 10 & 11 & 3.176 & $<0.001^{* *}$ \\
\hline 3 & Screen viewing and sleeping & 6 & 6.5 & 1.508 & 0.195 & 6 & 6 & 3.025 & $<0.001^{* *}$ \\
\hline 4 & Physical activity & 11 & 11 & 2.840 & 0.002 & 11 & 13 & 4.218 & $<0.001^{* *}$ \\
\hline
\end{tabular}

** Significant at $\mathrm{p}<0.001$.

Table 3 Comparison of Post test scores of Parameters Height, Weight and BMI between Control group and Experimental group:

\begin{tabular}{|c|l|l|c|c|}
\hline SI No & Parameter & Groups & Mean \pm SE & Unpaired t -test \\
\hline \multirow{2}{*}{1} & \multirow{2}{*}{ Height } & Control & $148.3 \pm 1.19$ & $\mathrm{t}=8.014$ \\
& & Experimental & $134.5 \pm 1.19$ & $\mathrm{p}<0.001^{* *}$ \\
\hline \multirow{2}{*}{2} & \multirow{2}{*}{ Weight } & Control & $46.6 \pm 1.62$ & $\mathrm{t}=5.81$ \\
& & Experimental & $34.9 \pm 1.25$ & $\mathrm{p}<0.001^{* *}$ \\
\hline \multirow{2}{*}{3} & \multirow{2}{*}{ BMI } & Control & $21.13 \pm 0.51$ & $\mathrm{t}=2.575$ \\
& & Experimental & $19.22 \pm 0.51$ & $\mathrm{p}<0.013$ \\
\hline
\end{tabular}

** Significant at $\mathrm{p}<0.001$.

Table 4 Shows comparison of Pre-test Post -test Mean \pm SE scores of Parameters measured in both Control and Experiment group in the study

\begin{tabular}{|c|c|c|c|c|c|}
\hline \multirow{2}{*}{ SI No } & \multirow{2}{*}{ Parameter } & \multirow{2}{*}{ Groups } & \multirow{2}{*}{ Mean $\pm \mathbf{S E}$} & \multicolumn{2}{|c|}{$\begin{array}{l}\text { Statistical analysis } \\
\text { Paired } t \text {-test }\end{array}$} \\
\hline & & & & $\begin{array}{l}\text { Con pre } \\
\text { Con post }\end{array}$ & $\begin{array}{l}\text { Exp pre } \\
\text { Exp post }\end{array}$ \\
\hline 1. & Height & $\begin{array}{l}\text { Control Pre } \\
\text { Experimental Pre } \\
\text { Control Post } \\
\text { Experimental Post }\end{array}$ & $\begin{array}{l}146.1 \pm 1.2 \\
132.6 \pm 1.2 \\
148.3 \pm 1.1 \\
134.5 \pm 1.1\end{array}$ & $\begin{array}{c}\mathrm{t} \text { value } \\
10.341 \\
\mathrm{p}<0.001^{* *}\end{array}$ & $\begin{array}{c}\mathrm{t} \text { value } \\
12.550 \\
\mathrm{p}<0.001^{* *}\end{array}$ \\
\hline
\end{tabular}




\begin{tabular}{|c|c|c|c|c|c|}
\hline \multirow{2}{*}{ SI No } & \multirow{2}{*}{ Parameter } & \multirow{2}{*}{ Groups } & \multirow{2}{*}{ Mean \pm SE } & \multicolumn{2}{|c|}{$\begin{array}{l}\text { Statistical analysis } \\
\text { Paired } t \text {-test }\end{array}$} \\
\hline & & & & $\begin{array}{l}\text { Con pre } \\
\text { Con post }\end{array}$ & $\begin{array}{l}\text { Exp pre } \\
\text { Exp post }\end{array}$ \\
\hline 2. & Weight & $\begin{array}{l}\text { Control Pre } \\
\text { Experimental Pre } \\
\text { Control Post } \\
\text { Experimental Post }\end{array}$ & $\begin{array}{l}46.5 \pm 1.6 \\
34.7 \pm 1.3 \\
46.7 \pm 1.6 \\
34.9 \pm 1.2\end{array}$ & $\begin{array}{c}\mathrm{t} \text { value } \\
0.940 \\
\mathrm{p}<0.359\end{array}$ & $\begin{array}{c}\text { t value } \\
0.947 \\
\mathrm{p}<0.353\end{array}$ \\
\hline 3. & $\begin{array}{l}\text { Body mass } \\
\text { index }\end{array}$ & $\begin{array}{l}\text { Control Pre } \\
\text { Experimental Pre } \\
\text { Control Post } \\
\text { Experimental Post }\end{array}$ & $\begin{array}{c}21.7 \pm 0.49 \\
19.6 \pm 0.53 \\
21.13 \pm 0.51 \\
19.2 \pm 0.51\end{array}$ & $\begin{array}{c}\mathrm{t} \text { value } \\
4.223 \\
\mathrm{p}<0.001^{* *}\end{array}$ & $\begin{array}{c}\mathrm{t} \text { value } \\
2.712 \\
\mathrm{p}<0.012\end{array}$ \\
\hline
\end{tabular}

** Significant at $\mathrm{p}<0.001$.

Table 5 Eating behavior problems among obese children (pre test and post test) of control group and experiment group of the study.

\begin{tabular}{|c|l|c|c|}
\hline SI No & Subscale & Groups & Mann Whitney rank sum test \\
\hline 1 & Food response & Pre Con-Exp & $\mathrm{t}=482, \mathrm{p}=0.620$ \\
$\mathrm{t}=417, \mathrm{p}=0.329$
\end{tabular}

*** Statistically not significant.

\section{Discussion}

The overall prevalence of obesity and overweight is $26 \%$ in this study. In a similar cross sectional study done in Telengana, it was found using IAP charts, $24.6 \%$ of children in class $4-10$ were obese while $35.8 \%$ were found to be overweight while using CDC criteria the prevalence seem to be $15.4 \%$ obese and $26.1 \%$ overweight. Further the mean BMI was found to be $25.6 \pm 3.5 \mathrm{~kg} / \mathrm{m}^{2}$ in the obese group and $21.1 \pm 1.9 \mathrm{~kg} / \mathrm{m}^{2}$ in the overweight category. Prevalence recorded was highest in 8-10 years of age group ${ }^{8}$. In the present study also the prevalence of overall overweight \& obesity is found to be higher in boys (29.8\%) than in girls $(21.8 \%)$. The study findings revealed that the prevalence of overweight $\&$ obesity among boys was higher compared to that among girls.

The study findings show statistical significance at $p<0.001$ in the obesity related behavior subscales in both pre test and post test scores of control group and experimental group. The obesity related behavior included for subscales-Dietary pattern, Emotional eating and attitude, Screen viewing \& sleeping and Physical activity. Similar study findings are reported in Michigan where sleep duration per night $(\mathrm{p}=0.04)$ and frequency 
of eating breakfast $(\mathrm{p}=0.04)$ show significant predictors of overweight and obesity ${ }^{9}$. In a study conducted in rural Coimbatore to find the effectiveness of multi strategic health screening cum educational intervention model in promoting health of school children shows similar findings like changes in dietary and personal assessment score. Even in the pre-post scores there are improved practices of nutrition and personal hygiene and pre-post mean scores were found to be statistically significant. The mean BMI distribution of the students in the pre and post intervention was found to be significant. Further the intervention had improved in the normal BMI category though it showed slight increase in the overweight and obese category. At the end of 6 months the intervention has shown improvement in total mean score of diet and personal hygiene assessment among students ${ }^{10}$.

The eating behavior scores in the study in pretest posttest done among both control and experimental group shows no statistical significance .In a population based prospective birth cohort study conducted among 3331 children in Netherlands to examine the longitudinal and bidirectional association between eating behavior and body composition. The BMI measurement at 6 years and 10 years were taken, body composition was measured using Fat mass index and Fat free mass index was measured using dual energy $x$ ray absorptiometry scans. Also eating behavior was measured using child eating behavior questionnaire. The study findings showed a higher BMI and high fat mass at preschool age. Further more food approaching and less food avoiding eating behaviors at 10 years of age were noticed. The study finally concludes stating that increased adiposity might increase appetite and eating related behavior ${ }^{11}$.

In a similar Structured Behavior Intervention Program on Childhood Obesity, which was done in Chennai to evaluate the effectiveness of Comprehensive School Health Manual (CSHM) among children through a Training of Trainers program for Central Board of Secondary Education (CBSE) school teachers, it was found that the overall prevalence of obesity was $12.6 \%$ with no difference in the incidence of obesity $(3.7 \%$ vs. $3.8 \%)$ at the end of the study period. Among the total participants, $65.4 \%$ in the intervention arm had a favorable shift in the nutritional grade. Further, there was a significant reduction in BMI z score $(-0.16)$ and body fat percentage $(-2.02)$ in the experiment group. The group reduced their calorie intake, but it was significantly lower in intervention arm -381.9 (95\% CI -428.2 to -335.4 ). Also, around $19.1 \%$ of children in the intervention group reduced their excess intake of junk food. There was a slight reduction in diastolic blood pressure $(-1.8)$ in the intervention group ${ }^{12}$.

Ina review study it was observed that there are multiple factors which influence the dietary habits in children. It mentions how certain strategies are to be taken to bring changes in establishing and promoting behaviors to prevent obesogenic environment in children by the family. The review encourages educational program to be offered to both parents and children to promote physical activity, reduce screen time and have adequate sleep ${ }^{13}$.

Similar results are reported in a community-based study approach involving both teachers and parents who were imparted nutrition and lifestyle interventions among adolescents to adopt a healthier lifestyle. The study shows positive behavioral changes and healthier eating choices ${ }^{14}$.

\section{Conclusion}

This study reported changes in the post-test scores of the experimental group and reduction or no increase in BMI, which is a significant finding after the intervention compared to the control group. This study indicated that the intervention was effective in bringing changes to the obesity-related behavior in the experimental group. The results are highly encouraging which interprets that if parents are involved as change agents then obesity in young children can be controlled.

\section{Conflict of Interest: None}

Source of Funding: Self funding

\section{Findings:}

\section{Reference}

1. Hill J O, Wyatt H R,Peters JC . Energy balance and Obesity.Circulation.2012; 126(1) :126-132.

2. W H Dietz. Critical periods in childhood for the development of obesity. The American Journal of Clinical Nutrition. 1994; 59(5).

3. Anna E K, Chamberlain K.L,Ejderhamn, J. Philip A. Fisher, Claude Marcus, Patricia Chamberlain et al. The More and Less Study: a randomized controlled trial testing different approaches to treat obesity in preschoolers. BMC Public Health. 2015;15: 735 
4. Kim HS, Park J, Park KY, Lee MN,Ham OK Parent Involvement Intervention in Developing Weight Management Skills for both Parents and Overweight/Obese Children. Asian Nurs Res (Korean Soc Nurs Sci).2016;10(1):11-17.

5. Barlow SE, Dietz WH. Obesity evaluation and treatment: Expert Committee recommendations. The Maternal and Child Health Bureau, Health Resources and Services Administration and the Department of Health and Human Services. Pediatrics. 1998 Sep;102(3):E29. doi: 10.1542/ peds.102.3.e29. PMID: 9724677.

6. Nayak BS, Bhat VH. School Based Multicomponent Intervention for Obese Children in Udupi District, South India - A Randomized Controlled Trial. J Clin Diagn Res. 2016;10(12):sc24-28.

7. Khadilkar VV, Khadilkar AV, Borade AB, Chiplonkar SA. Body mass index cut-offs for screening for childhood overweight and obesity in Indian children. Indian Pediatr. 2012;49:29-34.

8. Chandra N, Anne B, Venkatesh K, Teja G D, Katkam SK. Prevalence of childhood obesity in an affluent school in Telangana using the recent IAP growth chart: A pilot study. Indian J EndocrMetab. 2019;23:428-32.

9. Olson J, Aldrich H, Callahan TJ, Matthews EE, Gance-Cleveland B. Characterization of Childhood
Obesity and Behavioral Factors. J Pediatr Health Care. 2016 Sep-Oct;30(5):444-52.

10. Muhammad GM, Ganesan S, Chacko T V. Effectiveness of multi strategic health screening cum educational intervention model in promoting health of school children in rural Coimbatore. Indian J Public Health.2019; 63:133-8.

11. Derks,I.P.M.,Sijbrands,E.J.G., Wake, M. et al. Eating behavior and body composition across childhood: a prospective cohort study. IntJBehavNutr Phys Act .2018; 15(1):96.

12. Viswanathan V,Ali B A, Araviindalochanan V, Kuppusamy S, Rajan R \& Sathyamurthy S. Effect of structured behavior intervention program on childhood obesity. International Journal of Tropical Disease \& Health.2015; 11(4):1-8.

13. Scaglioni, Silvia \& De Cosmi, Valentina \& Ciappolino, Valentina \& Parazzini, Fabio \& Brambilla, Paolo \& Agostoni, Carlo. Factors Influencing Children's Eating Behaviours. Nutrients. 2018; 10: 706.

14. Singhal N, Misra A, Shah P, Gulati S. Effects of controlled school-based multi-component model of nutrition and lifestyle interventions on behavior modification, anthropometry and metabolic risk profile of urban Asian Indian adolescents in North India. Eur J Clin Nutr. 2010; 64(4):364-73. 